\title{
Electron microscopic observations on phosphatase activities at the chorioid plexus in rat brain \\ II. On the structural localization of $\beta$-glycerophosphatase at the alkali pH
}

\author{
By \\ Seiji Ishii and Shozo Matano \\ Department of Anatomy, Osaka University Medical School, Osaka, Japan \\ (Director: Professor Mototsugu Kohama)
}

In the previous paper, ${ }^{1)}$ we discussed the fine structural localization of $\beta$-glycerophosphatase activity at the acid $\mathrm{pH}$ in rat chorioid plexus. We are interested in this tissue viewed from its biological function, such as blood-cerebrospinal fluid barrier.2)

In this paper, we shall report on the structural localization of $\beta$-glycerophosphatase activity at the alkali $\mathrm{pH}$ compared with results of acid $\beta$-glycerophosphatase activity.

\section{Materials and Methods}

The chorioid plexus in six Sprague-Dawley rats weighing about $150 \mathrm{gr}$. were used for the experiment. The enzymic activity of $\beta$-glycerophosphatase at $\mathrm{pH}$ 8.8-9.0 was electronmicroscopically demonstrated as follows:

1) The rat was perfused for $20 \mathrm{~min}$. with $2 \%$ cold glutaraldehyde adjusted $\mathrm{pH} 7.4$ by cacodylate buffer.

2) Then, the chorioid plexus obtained from the lateral and IVth ventricles roofs in the rat brain was washed with cacodylate buffer containing $0.2 \mathrm{M}$ sucrose $(\mathrm{pH} 7.4)$ for $24 \mathrm{hrs}$. at $4^{\circ} \mathrm{C}$.

3) The material was immersed in the following medium* which is a modified form of the medium used by $\mathrm{M}$ öl bert et al. ${ }^{3)}$, for $30 \mathrm{~min}$. at $37^{\circ} \mathrm{C}$ and then washed briefly with $0.44 \mathrm{M}$ sucrose solution.

* $0.2 \mathrm{M}$ Tris maleate buffer

5.00 c. c.

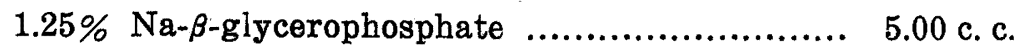

$1.0 \%$ lead nitrate

3.00 c. c. 


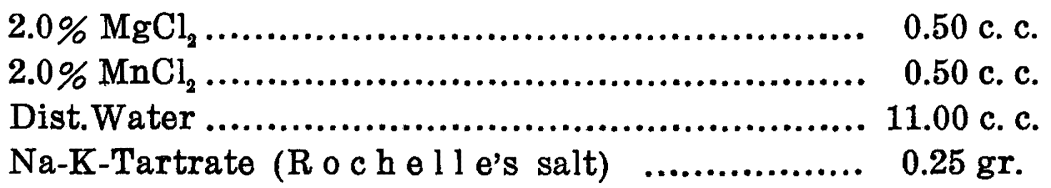

Final pH was adjusted pH 8.8-9.0. This solution could be used without filtration, because no white precipitate by lead was produced.

4) The material was refixed by $\mathrm{Ca}$ a $\mathrm{lf}$ ield's fixative fluid at pH 7.4 for $30 \mathrm{~min}$.

5) Then, it was dehydrated by alcohol, embedded in Epon 812 and cut into ultrathin section by LKB microtome. Electron microscopic observation was made by JEM 6C and HC 11B microscopes.

6) The sections were observed without any electron staining, because lead precipitation particles by electron staining are often confused with those by enzymic activity.

The following preparations were made as control in order to compare with experimental preparation.

1) Inhibition test of enzymic activity was held by use of the medium mentioned-above, in which $0.01 \mathrm{M}$ KCN was added.

2) For non-specific lead precipitation test, preparation was made by $3 \% \mathrm{Na}-\beta$-glycerophosphate free medium.

3) For light microscopy, the material immersed in the abovementioned medium was treated by dilute ammonium sulfide solution.

\section{Results}

Positive reaction of $\beta$-glycerophosphatase activity at the alkali $\mathrm{pH}$ 8.8-9.0 is always observed at sites of the plasma membranes of the microvilli (Fig. 1) and of the basal infolding (Fig. 2) of the chorioid epithelium. The junctional part of two chorioid epithelial cells also shows the positive reaction of this enzymic activity (Figs. 1 3). Moreover, the fibrocyte in the part of connective tissue between the epithelial part and capillary one reveals the positive reaction of this enzymic activity (Fig. 4). The endothelial cell of the capillary wall shows the positive reaction, too (Fig. 4).

No positive reaction of this enzymic activity is shown at the mitochondria, endoplasmic reticulum, nucleus, nucleolus and the nuclear envelope in the chorioid epithelium. We could not recognize the positive reaction at the lysosome and the Golgi's cisternae (Fig. 3). In the capillary wall of the chorioid plexus, the fenestration can usually be observed, but no positive reaction of this enzymic activity is shown at 
this site (Fig. 4).

Regarding non-specific lead precipitation test by $3 \% \quad \beta$-glycerophosphate free medium, the lead precipitate did not exist at any site in the chorioid plexus.

\section{Discussions}

According to Gomori's method') for demonstration of alkaline phosphatase; white precipitate is always caused by lead at making the substrate medium. But $\mathrm{R}$ och elle's salt (Na-K-tartrate) prevents the precipitation by lead in this medium as reported by Mölbert et al. ${ }^{3)}$. Our modification method showed a good result concerning the demonstration for alkaline phosphatase activity under the electron microscope.

Alkaline phosphatase activity in various animal tissues has been studied by a few researchers at the electron microscopic level. ${ }^{5)-6)}$ But some differences of opinion exist concerning to sites of positive reaction of this enzymic activity. $H \mathrm{ug} n$ and $\mathrm{B}$ orger $\mathrm{s}^{6)}$ recognized the positive activity at the smooth reticulum cisternae, Golgi's zone and the dense body in the absorbing cells of the duodenum. By our observations, sites mentioned-above by $\mathrm{H} \mathrm{u} \mathrm{g}$ o $\mathrm{n}$ and Borgers did not show any positive reaction in the chorioid epithelium (Fig. 3). It may be caused by the functional difference based upon organ specifity.

We are very interested in positive reactions of this enzymic activity at the plasma membranes of the microvilli and of the basal infolding of the chorioid epithelium (Figs. 1 3). As reported in the previous paper ${ }^{1)}$, these sites also showed the positive reaction of $\beta$-glycerophosphatase at the acid $\mathrm{pH}$. These facts may have a close relationship with the biological functions of the chorioid plexus as the blood-cerebrospinal fluid barrier. Regarding these problems, the experimental results of ATP-ase and other enzymic activities will be reported in future.

\section{Summary}

1) The structural localization of $\beta$-glycerophosphatase activity at the alkali $\mathrm{pH}$ 8.8-9.0 was demonstrated in rat chorioid plexus by means of electron microscope.

2) Positive reaction of this enzymic activity was observed at the plasma membranes of the microvilli and of the basal infolding 
of the chorioid epithelium. The junctional part of two chorioid epithelial cells also showed the positive activity.

3) The endothelial cell of the capillary wall and the fibrocyte in the connective tissue revealed the positive reaction of this enzymic activity.

4) No positive reaction of this enzymic activity was demonstrated in the mitochondria, Golgi's cisternae, lysosome, endoplasmic reticulum, nucleus, nucleolus and the nuclear envelope in the chorioid epithelium. And also, the positive reaction could not be recognized at the site of the fenestration in the capillary wall.

5) A special interest related to the function was focused to the plasma membranes of the microvilli and of the basal infolding in the chorioid epithelium, at which positive reactions of both alkaline and acid $\beta$-glycerophosphatase activities were revealed.

\section{Acknowledgement}

We greatly appreciate the support for this work by Professor Mototsugu Kohama, Chairman of Department of Anatomy, Osaka University Medical School.

\section{References}

1) Matano, S. \& Ishii, S.: Electron microscopic observations on phosphatase activities at the chorioid plexus in rat brain. I. On the structural localization of $\beta$-glycerophosphatase at the acid pH. Okajimas Fol. anat. jap., $44: 1-9,1967$.

2) Edström, R.: Recent developments of the blood-brain barrier concept. Intern. Rev. Neurobiol., $7:$ 153-190, 1964.

3) Mölbert, R.G., Dus pia, F. \& Deimling, O.H.: The demonstration of alkaline phosphatase in the electron microscope. J. Biophys. Biochem. Cytol., $7: 387-390$, 1960.

4) L is o n, L.: Histochimie et Cytochimie animales. Gauthier-Villars and Co. Paris, 1960.

5) Cla rk, S.L.Jr.: The localization of alkaline phosphatase in tissues of mice, using the electron microscope. Am. J. Anat., 109 : 57-83, 1961.

6) Hu g o n, J. \& Borgers, M.: Ultrastructural localization of alkaline phosphatase activity in the absorbing cells of the duodenum. J. Histochem. Cytochem., 14:629640, 1966. 


\section{Explanation of Figures}

Fig. 1. Numerous microvilli of the chorioid epithelium are shown. Fine lead precipitates by alkaline $\beta$-glycerophosphatase activity can be observed at the plasma membranes of microvilli and at the junctional part of two chorioid epithelial cells (Arrows). The mitochondria (M) do not show the positive reaction. No electron staining. $\times 24,000$.

Fig. 2. The positive reaction of this enzymic activity is recognized at the basal infolding of the chorioid epithelium and the junctional part of two chorioid epithelial cells (Arrow). The mitochondria do not show the positive reaction. No electron staining. $\times 22,000$.

Fig. 3. No positive reaction of this enzymic activity is shown at the mitochondria and the Golgi's cisternae (G). On the other hand, the positive reaction can be found at the basal infolding of the chorioid epithelium and the junctional part of two chorioid epithelial cells (Arrows). No electron staining. $\times 22,000$.

Fig. 4. The fibrocyte in the connective tissue and the endothelial cell of the capillary wall show the positive reaction of this enzymic activity. No positive reaction is revealed at the fenestration in the capillary wall (Arrows). L : capillary lumen. No electron staining. $\times 22,000$. 
Plate I
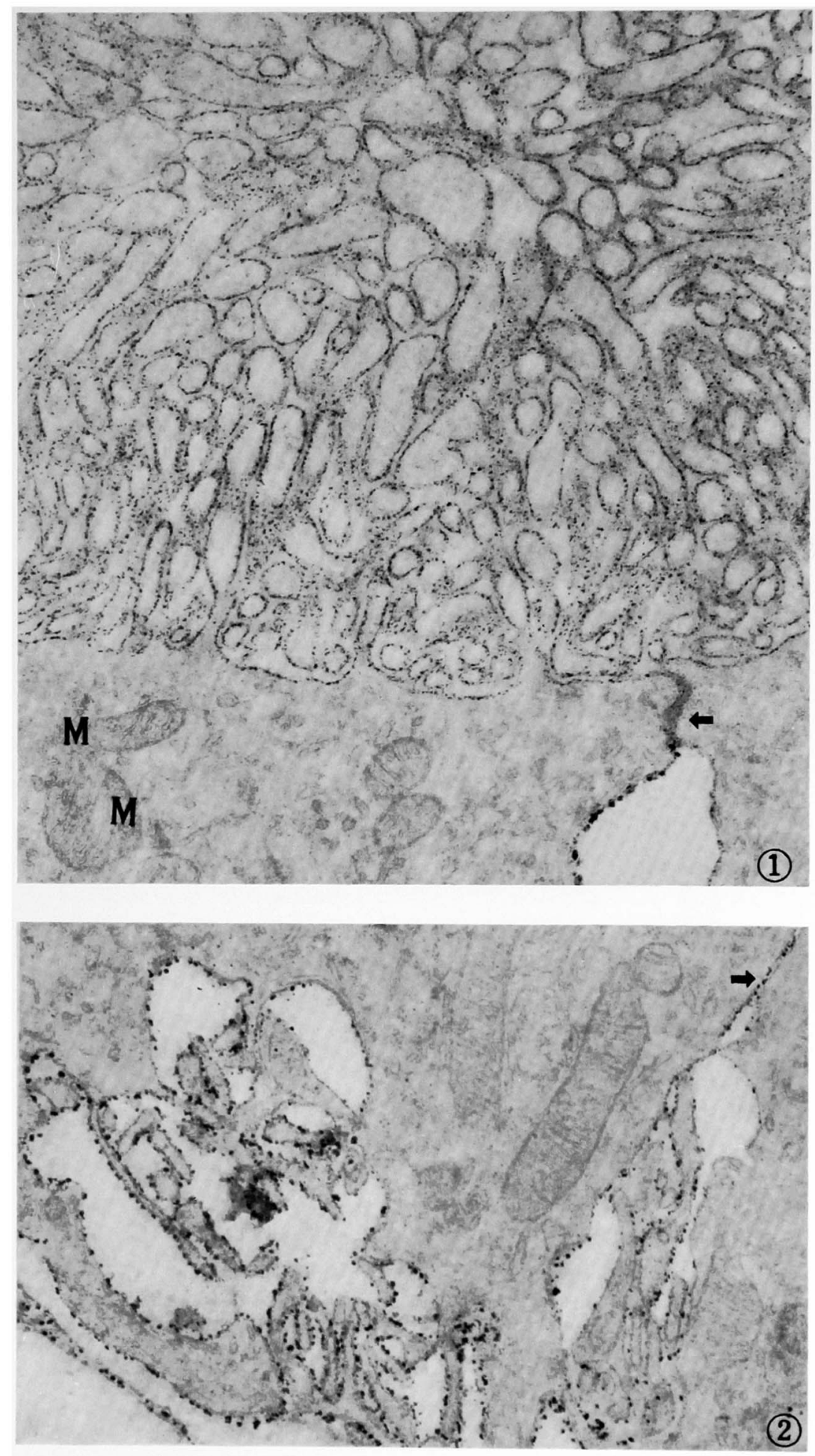
Plate II
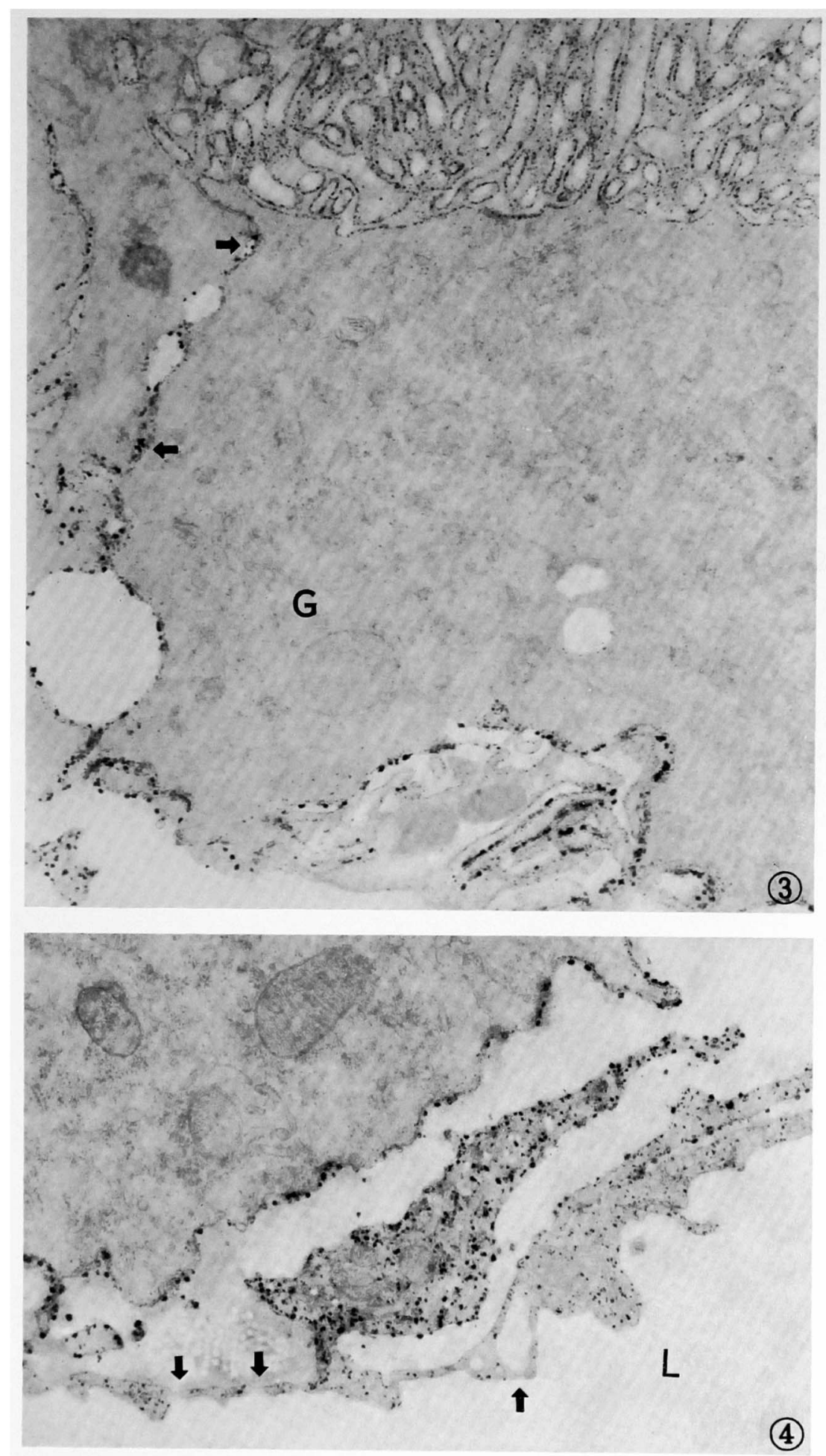

S. Ishii and S. Matano 